\title{
Aspartic Acid Synthesis of Crystalline Gold Nanoplates, Nanoribbons and Nanowires in Aqueous Solutions
}

\author{
Yen Nee Tan, ${ }^{b}$ Jim Yang Lee, ${ }^{\text {a,b }}$ and Daniel I.C. Wang ${ }^{\text {b,c }}$
}

${ }^{a}$ Department of Chemical and Biomolecular Engineering, National University of Singapore.

10 Kent Ridge Crescent, Singapore 119260. Fax: 656779 1936; Tel: 656516 2899; E-mail:

$$
\text { cheleejy@nus.edu.sg }
$$

${ }^{\mathrm{b}}$ Singapore-MIT Alliance, 4 Engineering Drive 3, National University of Singapore,

Singapore 117576

${ }^{\mathrm{c}}$ Department of Chemical Engineering, Massachusetts Institute of Technology

Room 16-429, 77 Massachusetts Ave, Cambridge MA 02139 USA 


\section{Supporting Information}
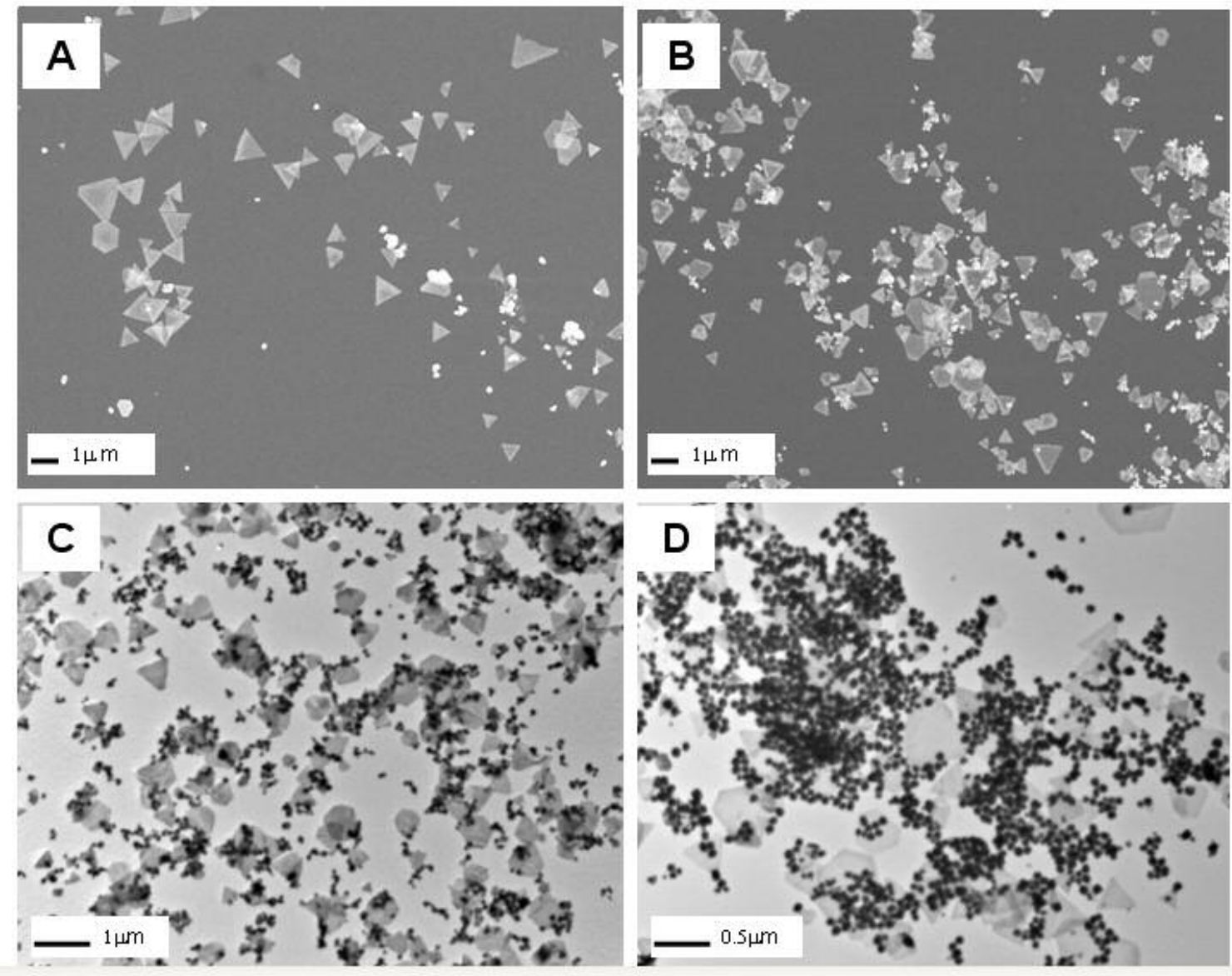

Figure S1. FESEM and TEM images of samples prepared at $\left[\mathrm{HAuCl}_{4}\right]=0.50 \mathrm{mM}$ with increasing [Asp] of $0.25,0.50,1.00$ and $2.50 \mathrm{mM}(\mathrm{A}-\mathrm{D})$. 

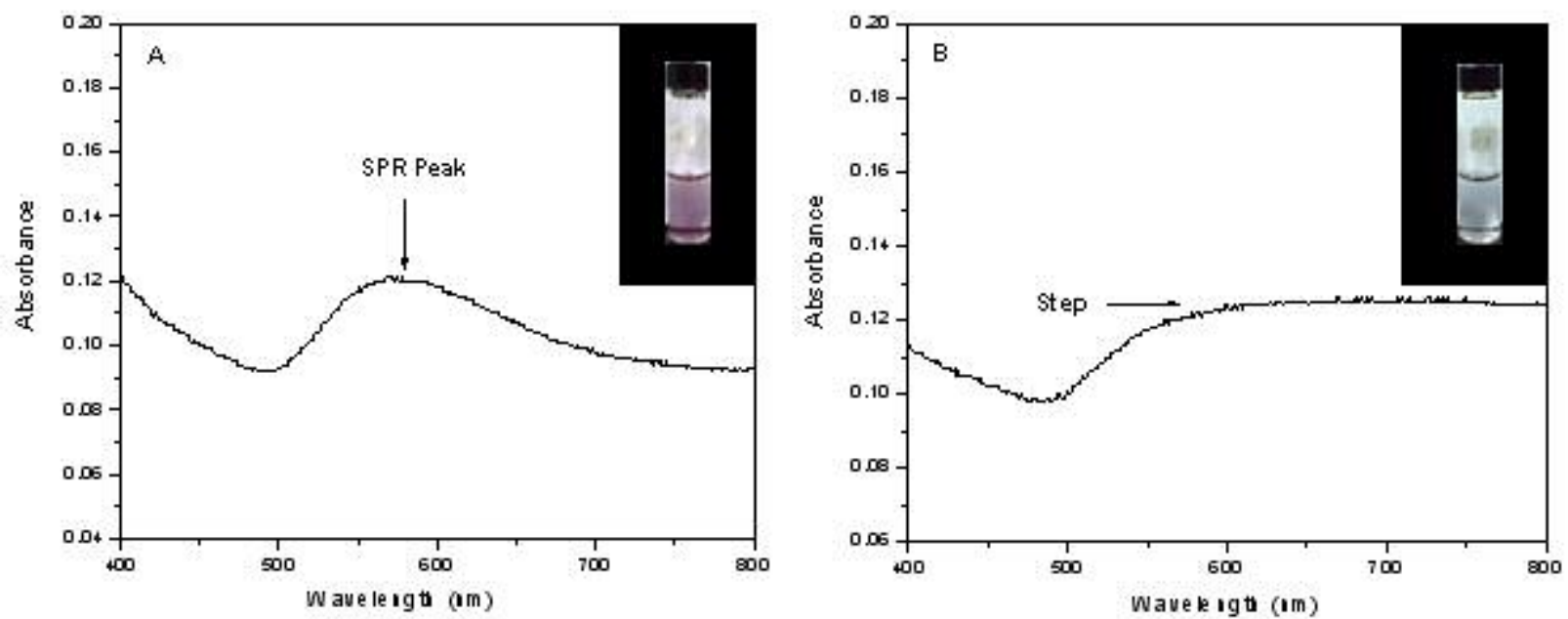

Figure S2. UV-vis spectra of samples prepared at $\mathrm{R}=0.5$ and $(\mathrm{A})\left[\mathrm{HAuCl}_{4}\right]=0.50 \mathrm{mM}$ and (B) $\left[\mathrm{HAuCl}_{4}\right]=0.10 \mathrm{mM}$. The inset at the top-right corner shows the solution color of the respective sample. 